Article

\title{
Nanostructured Silver Coating as a Stationary Phase for Capillary Gas Chromatography
}

\author{
Qiong Jiang ${ }^{1, *}$, Peng $\mathrm{Xu}^{1}$, Juanjuan Feng ${ }^{2}$ and Min Sun ${ }^{2, *}$ \\ 1 College of Plant Protection, Gansu Agricultural University/Biocontrol Engineering Laboratory of Crop \\ Diseases and Pests of Gansu Province, Lanzhou 730070, China; xupeng@gsau.edu.cn \\ 2 Key Laboratory of Interfacial Reaction \& Sensing Analysis in Universities of Shandong, School of Chemistry \\ and Chemical Engineering, University of Jinan, Jinan 250022, China; chm_fengjuanjuan@ujn.edu.cn \\ * Correspondence: menghuanrou@163.com (Q.J.); chm_sunm@ujn.edu.cn (M.S.); \\ Tel.: +86-931-7632260 (Q.J.); +86-531-89736065 (M.S.)
}

Received: 27 September 2019; Accepted: 2 December 2019; Published: 8 December 2019

\begin{abstract}
A capillary column coated with nanostructured silver coating was fabricated for gas chromatography. The nanostructured silver coating, about 80-120 nm in thickness, was prepared as the stationary phase via silver mirror reaction, and was characterized by SEM and EDS. The column was evaluated using different types of model analytes, including $n$-alkanes, $n$-alcohols, benzenes, and Grob mixture. A baseline separation of ten $n$-alkanes on the silver column $(15 \mathrm{~m} \times 0.20 \mathrm{~mm}$ i.d.) was achieved within $3.5 \mathrm{~min}$ through the main hydrophobic mechanism. A mixture of six $n$-alcohols, or another mixture containing three butanol isomers and two octanol isomers, was separated well on the column. The column separated some benzenes containing benzene, toluene, ethylbenzene, $p$-xylene, o-xylene, styrene, benzaldehyde, and benzyl alcohol. A Grob mixture containing seven analytes was also separated successfully. Based on a multiple retention mechanism such as hydrophobic, dipole-dipole, and dipole-induced dipole interactions, the silver column achieved a good separation of twelve different types of compounds within $2.5 \mathrm{~min}$. The column presented satisfactory separation repeatability with relative standard deviation of retention time between $0.073 \%$ and $0.591 \%$. The results indicate that the silver column is promising for gas chromatographic separation.
\end{abstract}

Keywords: silver coating; nanomaterial; capillary column; gas chromatography; organic compounds

\section{Introduction}

Nanoparticles have attracted great attention due to their unique properties and potential in separation science. Various nanoparticles were applied for solid-phase extraction [1-3], solid-phase microextraction [4-7], removal of pollutants [8,9], and chromatographic stationary phase [10,11]. Carbon nanomaterials like carbon nanotubes (CNTs) and graphene oxide (GO) were used as the stationary phases for gas chromatography (GC), which exhibited excellent separation performance for various organic compounds. Based on a large number of active sites and the ability to provide $\pi-\pi$ stacking [12], GC columns with CNTs could separate volatile aromatic or unsaturated organic compounds, such as polycyclic aromatic hydrocarbons, n-alkanes, and alcohols [13-16]. Using GO as the stationary phase separated a wide range of organic mixtures, including alcohols and aromatic compounds, which provided a high surface area to increase the phase ratio and rich functional groups for the formation of hydrophobic, hydrogen bonding, and $\pi-\pi$ stacking interactions [17]. Graphitic carbon nitride-coated GC columns exhibited high-resolution capabilities for aromatic and aliphatic isomers such as methylnaphthalenes and dimethyl-naphthalenes, phenanthrene and anthracene, as well as alkane isomers [18], by advantage of unique retention mechanisms, including $\pi-\pi$ stacking, 
hydrogen bonding, halogen bonding, and dispersion interactions. Gold nanoparticles modified with organic groups were also explored as the GC stationary phase [19-22]. A square capillary column coated with dodecanethiol monolayer-protected gold nanoparticles quickly separated a seven-component mixture (methyl ethyl ketone, benzene, octane, chlorobenzene, anisole, 3-octanone, and decane) in only $2 \mathrm{~s}$ [19-21]. The octadecylamine-capped gold nanoparticles were directly used to modify the capillary wall for GC, and the hydrophobic coating separated various types of analytes (benzene, 1-butanol, 1-pentanol, chlorobenzene, anisole) [22].

Silver nanoparticles have unique characteristics like good antibacterial activity [23] and adsorption performance for some organics [24]. Micro-structured silver coating or surface exhibited satisfactory extraction performance for polycyclic aromatic hydrocarbons and phthalate esters [25,26]. In order to explore the chromatographic performance of silver nanomaterials, a capillary column coated with a nanostructured silver coating was fabricated for GC in this work. The column was evaluated with different types of organic compounds, such as alkanes, bromoalkanes, alcohols, benzenes, and the Grob mixture.

\section{Results and Discussion}

\subsection{Characterization of the Silver Capillary Column}

After the modification of silica capillary with a silver coating, the silver capillary column shows a silver-white color in Figure 1a. As can be seen from Figure 1c, the inner surface of bare silica capillary is smooth, and no obvious change is observed after the modification by 3-mercaptopropyltrimethoxysilane in Figure 1d. However, the inner surface is densely covered by a rough coating through the functionalization of silver coating in Figure 1e. According to the EDS spectrum of the inner surface (Figure S1 in Supplementary material), the coating is confirmed as a silver coating. As shown in Figure $1 \mathrm{f}$, the silver coating is very uniform with a thickness of about $80-120 \mathrm{~nm}$. It was calculated as about $20 \mathrm{mg}$ according to the concentration of $\left[\mathrm{Ag}\left(\mathrm{NH}_{3}\right)_{2}\right]^{+}$and the volume of capillary column. The silver coating is rough, which is favorable to chromatographic retention due to increasing active sites and contact area with the analyte. 


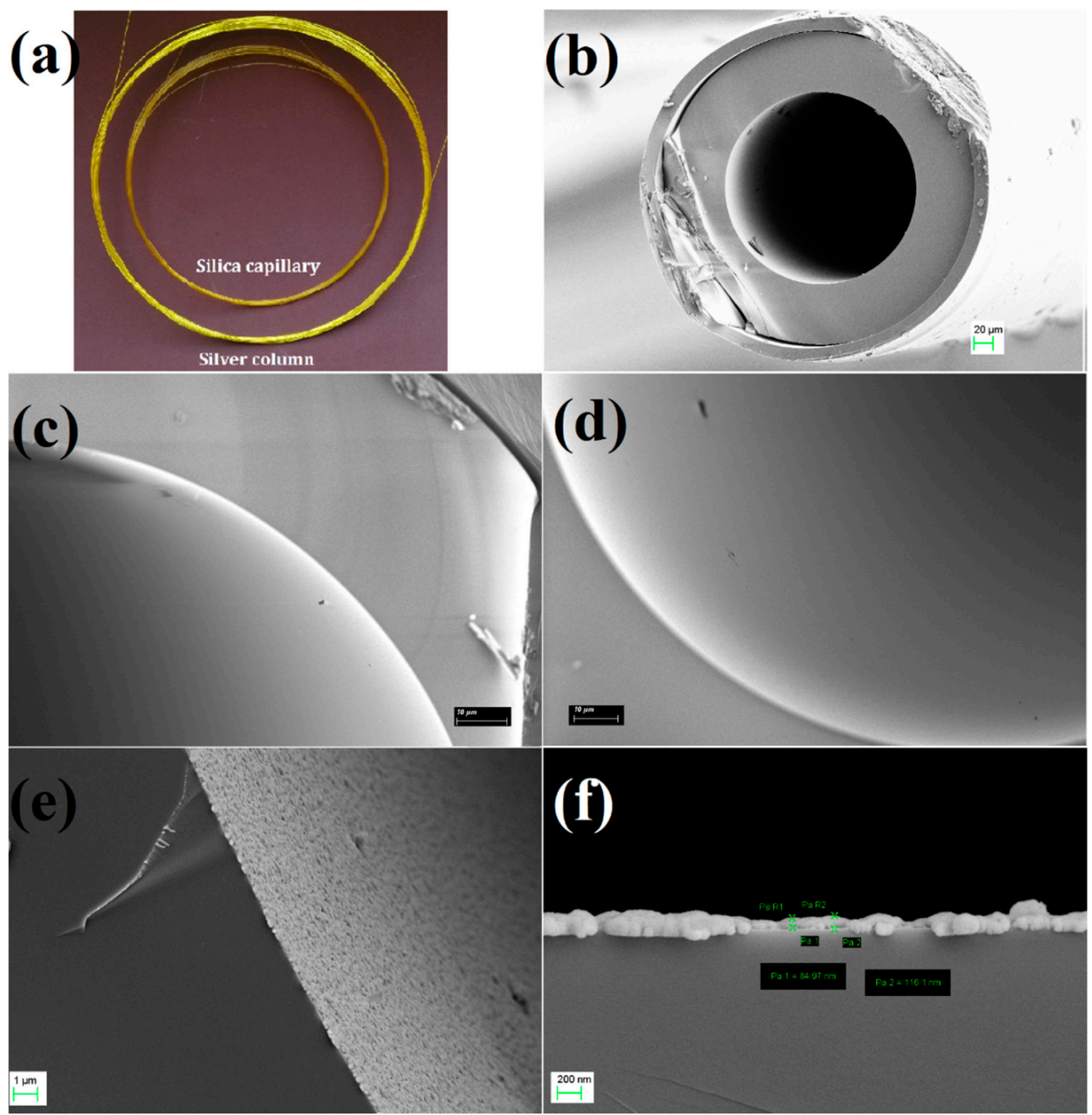

Figure 1. Photo of silver column (a) and SEM images (b-f), including the silver column (b), the inner surface of silica capillary (c), the inner surface of silica capillary modified with 3-mercaptopropyltrimethoxysilane (d), and the inner surface of silica capillary modified with silver coating $(\mathbf{e}, \mathbf{f})$.

\subsection{Investigation of the Flow Rate}

It is known that the chromatographic behavior of the column is dependent on the flow rate of the carrier gas. As shown in Figure 2a, the Van Deemter plot of the silver column is investigated with ethyl ether and tetrahydrofuran at $55{ }^{\circ} \mathrm{C}$. The highest column efficiency occurs under a linear velocity of around $9 \mathrm{~cm} \mathrm{~s}^{-1}$. The minimum height equivalent theoretical plate (HETP) is $0.46 \mathrm{~mm}$ for ethyl ether and $0.43 \mathrm{~mm}$ for tetrahydrofuran, which correspond to 2174 and 2326 plates $\mathrm{m}^{-1}$, respectively. It also indicated that the column efficiency was only slightly affected, even when a higher carrier gas flow rate was used. 

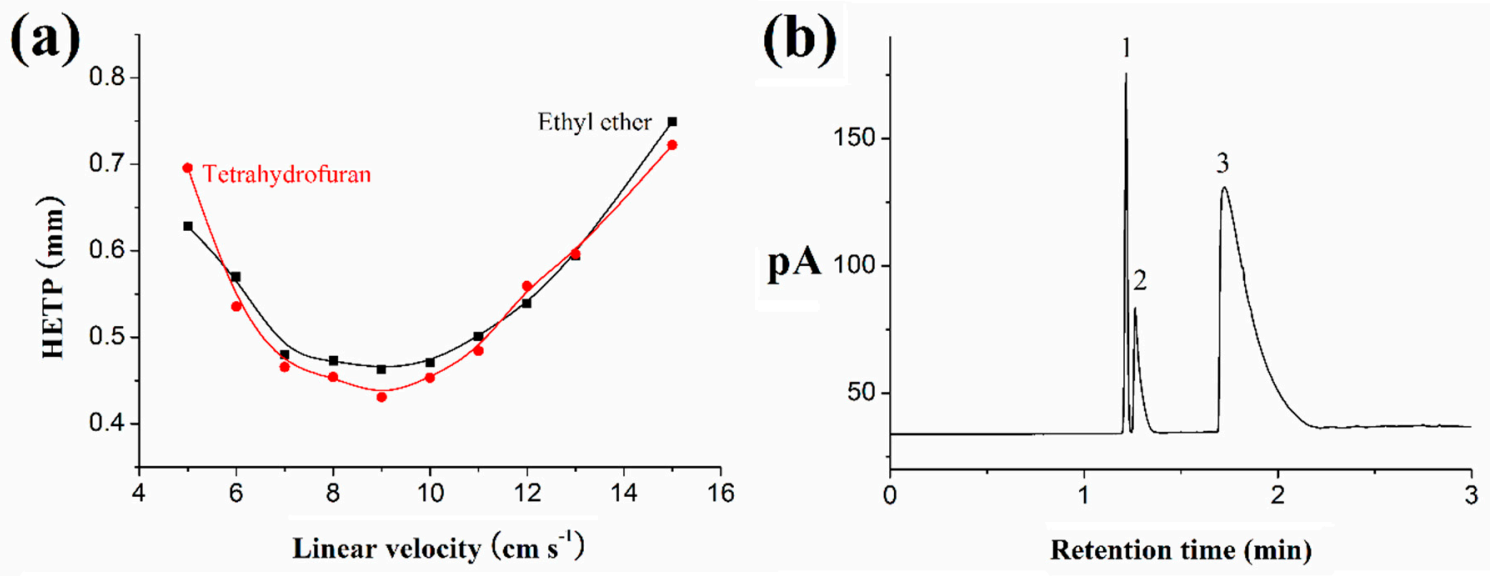

Figure 2. The Van Deemter plot for the silver column with ethyl ether and tetrahydrofuran at $55{ }^{\circ} \mathrm{C}(\mathbf{a})$, and the chromatogram of the polarity characterization (b). (b) Conditions: the carrier gas held at 0.3 $\mathrm{mL} \min ^{-1}$ for $1.2 \mathrm{~min}$ and up to $4 \mathrm{~mL} \mathrm{~min}^{-1}$ at a rate of $5 \mathrm{~mL} \mathrm{~min}^{-1}$; the injection volume was $0.01 \mu \mathrm{L}$; the injection split was 100:1. Peaks: cyclohexane (1), benzene (2), and pyridine (3).

\subsection{Characterization of the Polarity of Silver Column}

Three compounds containing cyclohexane (b.p. $80.7^{\circ} \mathrm{C}$ ), benzene (b.p. $80.1^{\circ} \mathrm{C}$ ), and pyridine were used to evaluate the polarity of the silver column. Cyclohexane and benzene are nonpolar compounds, but benzene is easily polarized. Pyridine is polar. If the silver column is a nonpolar column, the retention time of cyclohexane should be larger than that of benzene. If it is a polar column, pyridine should be more retained than benzene. Figure $2 b$ shows that benzene is more retained than cyclohexane, indicating that the silver column is polar. Pyridine is more retained than benzene, which also further illustrates the polarity of the silver column.

\subsection{Chromatographic Separation of the Silver Column}

\subsubsection{Separation of Alkanes}

The chromatographic separation of $n$-alkanes with a carbon number of about 6-14 and 16 was tested on the silver column. The chromatographic parameters were optimized to achieve a baseline separation for ten components. As shown in Figure $3 a$, the baseline separation of all $n$-alkanes was completed in only $3.5 \mathrm{~min}$ with the column temperature ramping from $30^{\circ} \mathrm{C}$ (held $1.8 \mathrm{~min}$ ) to $140{ }^{\circ} \mathrm{C}$ at a rate of $50{ }^{\circ} \mathrm{C} \mathrm{min}^{-1}$ and the flow rate of the carrier gas ramping from $0.2 \mathrm{~mL} \mathrm{~min}^{-1}$ (held $1.8 \mathrm{~min}$ ) to

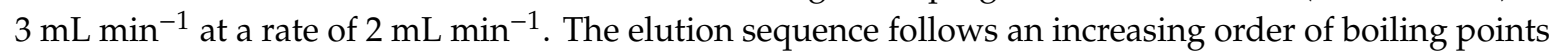
and the carbon numbers of all the analytes. Silver coating with a good control over surface roughness can produce hydrophobic characteristic [27-29]. Considering the nonpolarity and hydrophobicity of $n$-alkanes, the chromatographic separation might be attributed to van der Waals force between the linear alkanes and the hydrophobic silver coating of the column. In addition, the retention interaction is closely related to the carbon number of $n$-alkanes. Several 1-bromoalkanes were also separated well on the silver column based on this chromatographic mechanism (Figure S2 in Supplementary material). Furthermore, a mixture containing ten $n$-alkanes and two 1-bromoalkanes was successfully separated in only $3.0 \mathrm{~min}$ (Figure 3b). 
(a)

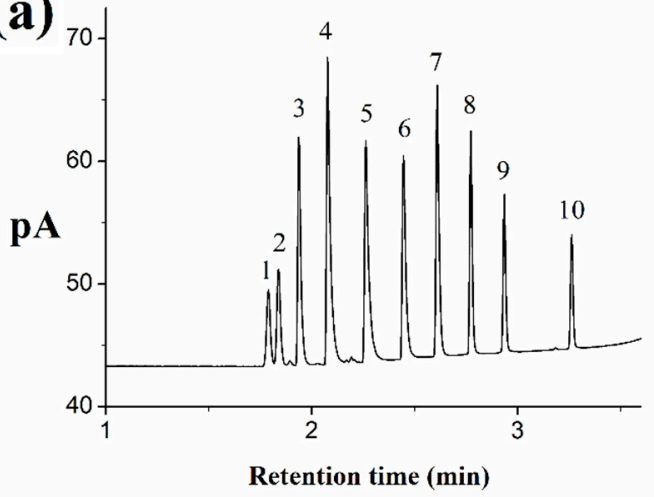

(c)

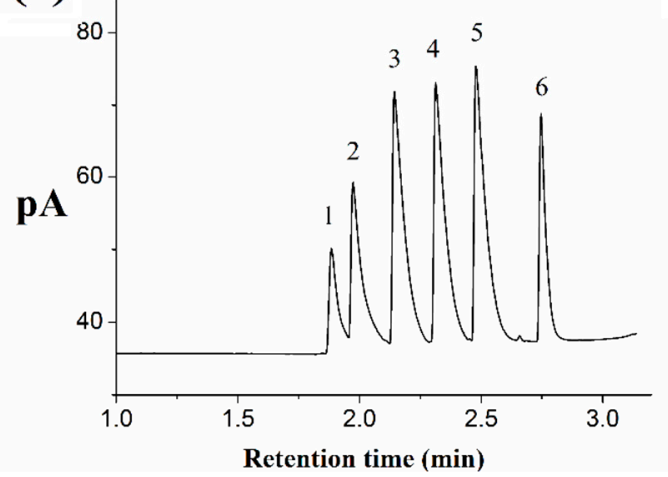

(b)

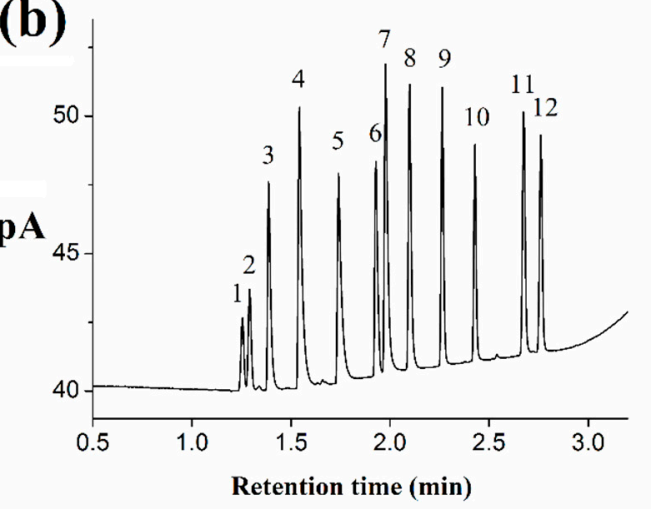

(d)

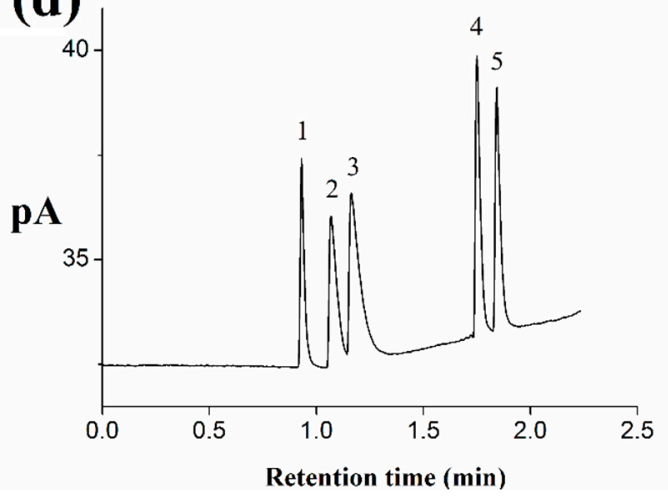

Figure 3. The chromatographic separation of ten $n$-alkanes (a), $n$-alkanes and 1-bromoalkanes (b), six $n$-alcohols (c), and the butanol isomers (d). (a) Conditions: held at $30^{\circ} \mathrm{C}$ for $1.8 \mathrm{~min}$ and up to $140{ }^{\circ} \mathrm{C}$ for $15 \mathrm{~min}$ at a rate of $50^{\circ} \mathrm{C} \mathrm{min}^{-1}$; the flow rate of the carrier gas held at $0.2 \mathrm{~mL} \mathrm{~min}{ }^{-1}(10 \mathrm{~cm}$

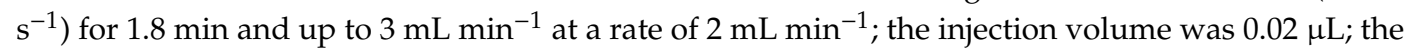
injection split was 100:1. Chromatographic peaks: $n$-hexane (1), $n$-heptane (2), n-octane (3), $n$-nonane (4), $n$-decane (5), n-undecane (6), $n$-dodecane (7), $n$-tridecane (8), $n$-tetradecane (9), and $n$-hexadecane (10). (b) Conditions: held at $30^{\circ} \mathrm{C}$ for $1.3 \mathrm{~min}$ and up to $140{ }^{\circ} \mathrm{C}$ for $15 \mathrm{~min}$ at a rate of $70{ }^{\circ} \mathrm{C} \mathrm{min}{ }^{-1}$; the flow rate of the carrier gas held at $0.3 \mathrm{~mL} \mathrm{~min}^{-1}$ for $1.3 \mathrm{~min}$ and up to $3 \mathrm{~mL} \mathrm{~min}^{-1}$ at a rate of $2 \mathrm{~mL} \mathrm{~min}^{-1}$; the injection volume was $0.02 \mu \mathrm{L}$; the injection split was 100:1. Chromatographic peaks: $n$-hexane (1), n-heptane (2), n-octane (3), n-nonane (4), n-decane (5), n-undecane (6), 1-bromooctane (7), $n$-dodecane (8), $n$-tridecane (9), n-tetradecane (10), $n$-hexadecane (11), and 1-bromododecane (12). (c) Conditions: held at $28{ }^{\circ} \mathrm{C}$ for $2 \mathrm{~min}$ and up to $100{ }^{\circ} \mathrm{C}$ at a rate of $80{ }^{\circ} \mathrm{C} \mathrm{min}{ }^{-1}$; the flow rate of carrier gas held at $0.2 \mathrm{~mL} \mathrm{~min}^{-1}$ for $2 \mathrm{~min}$ and up to $3 \mathrm{~mL} \mathrm{~min} \mathrm{~m}^{-1}$ at a rate of $3 \mathrm{~mL} \mathrm{~min}^{-1}$; the injection volume was $0.02 \mu \mathrm{L}$; the injection split was 100:1. Chromatographic peaks: methanol (1), n-propanol (2), $n$-butanol (3), $n$-pentanol (4), $n$-hexyl alcohol (5), and n-octanol (6). (d) Conditions: held at $25^{\circ} \mathrm{C}$ for $1 \mathrm{~min}$ and up to $100{ }^{\circ} \mathrm{C}$ at a rate of $60^{\circ} \mathrm{C} \mathrm{min}{ }^{-1}$; the flow rate of carrier gas from $0.46 \mathrm{~mL} \mathrm{~min}{ }^{-1}(20 \mathrm{~cm}$ $\mathrm{s}^{-1}$ ) up to $3 \mathrm{~mL} \mathrm{~min}^{-1}$ at a rate of $3 \mathrm{~mL} \mathrm{~min}^{-1}$; the injection volume was $0.02 \mu \mathrm{L}$; the injection split was 100:1. Chromatographic peaks: tert-butanol (1), isobutanol (2) $n$-butanol (3), ethylhexanol (4), and n-octanol (5).

\subsubsection{Separation of Alcohols}

Alcohols were also applied to investigate the silver column. Six $n$-alcohols are separated in Figure $3 c$, but their peaks are tailing. The elution sequence follows an increasing order of their boiling points (methanol $64.5^{\circ} \mathrm{C}, n$-propanol $97.1^{\circ} \mathrm{C}$, $n$-butanol $117.7^{\circ} \mathrm{C}, n$-pentanol $128^{\circ} \mathrm{C}$, $n$-hexyl alcohol $157.2^{\circ} \mathrm{C}$, and $n$-octanol $195^{\circ} \mathrm{C}$ ). Hydrophobic interaction may play a main role in the retention of alcohols on the column, the irreversible adsorption sites, and the polar property of silver stationary phase result in tailing peaks. The silver column can separate isomers of alcohols. Three butanol isomers 
(tert-butanol, isobutanol, and $n$-butanol) and two octanol isomers (ethylhexanol and $n$-octanol) are separated well in Figure 3d.

\subsubsection{Separation of Benzenes}

As shown in Figure 4a, some benzenes containing benzene, toluene, ethylbenzene, $p$-xylene, $o$-xylene, styrene, benzaldehyde, and benzyl alcohol are successfully separated by the silver column. Except the resolutions of ethylbenzene/p-xylene and $o$-xylene/styrene, which are less than 2, the resolutions among other benzenes are larger than 2. Chromatographic separation of ethylbenzene and xylene isomers is challenging because of their coherent boiling points and dimensions. The silver column can efficiently separate these compounds. The resolutions of ethylbenzene $/ p$-xylene and $p$-xylene/o-xylene are 1.22 and 2.01, respectively. Compared with ethylbenzene, styrene is better retained on the silver column due to its larger $\pi$-electron.
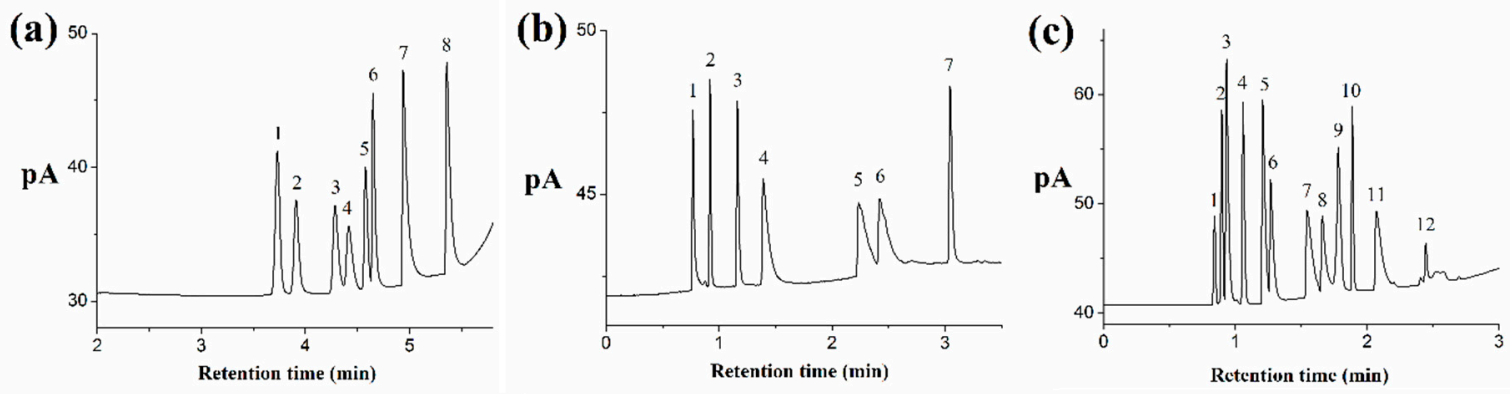

Figure 4. The chromatographic separation of benzenes (a), the Grob mixture (b), and the mixture of different types of compounds (c). (a) Conditions: held at $28{ }^{\circ} \mathrm{C}$ for $4.5 \mathrm{~min}$ and up to $140{ }^{\circ} \mathrm{C}$ at a rate of $80{ }^{\circ} \mathrm{C} \mathrm{min}^{-1}$; the flow rate of carrier gas from $0.1 \mathrm{~mL} \mathrm{~min}^{-1}$ up to $4 \mathrm{~mL} \mathrm{~min}^{-1}$ at a rate of $4.5 \mathrm{~mL} \mathrm{~min}^{-1}$; the injection volume was $0.02 \mu \mathrm{L}$; the injection split was 100:1. Chromatographic peaks: benzene (1), toluene (2), ethylbenzene (3), $p$-xylene (4), o-xylene (5), styrene (6), benzaldehyde (7), and benzyl alcohol (8). (b) Conditions: held at $50{ }^{\circ} \mathrm{C}$ for $1.5 \mathrm{~min}$ and up to $100{ }^{\circ} \mathrm{C}$ at a rate of $60{ }^{\circ} \mathrm{C} \mathrm{min}-1$; the carrier gas was $0.5 \mathrm{~mL} \mathrm{~min}^{-1}$; the injection volume was $0.02 \mu \mathrm{L}$; the injection split was 100:1. Chromatographic peaks: methanol (1), n-decane (2), n-undecane (3), n-nonaldehyde (4), 2,6-dimethylaniline (5), 2,6-dimethylphenol (6), and methyl dodecanoate (7). (c) Conditions: held at $35^{\circ} \mathrm{C}$ for $1 \mathrm{~min}$ and up to $140{ }^{\circ} \mathrm{C}$ at a rate of $60^{\circ} \mathrm{C} \mathrm{min}^{-1}$; the carrier gas held at $0.5 \mathrm{~mL} \mathrm{~min}{ }^{-1}$ for 1 min and up to $3 \mathrm{~mL} \mathrm{~min}{ }^{-1}$ at a rate of $3 \mathrm{~mL} \mathrm{~min}^{-1}$; the injection volume was $0.02 \mu \mathrm{L}$; the injection split was 100:1. Chromatographic peaks: $n$-hexane (1), n-heptane (2), 1-bromobutane (3), n-octane (4), p-xylene (5), o-xylene (6), cyclohexanone (7), benzaldehyde (8), 1-bromooctane (9), $n$-dodecane (10), benzyl alcohol (11), and 1-bromododecane (12).

\subsubsection{Separation of the Grob Mixture}

The Grob mixture is a test mixture for the comprehensive assessment of the overall chromatographic performance and activity of the GC column. Resolution, elution order, and peak shape of analytes are indicative of their retention behavior on the given column [30]. Figure $4 \mathrm{~b}$ shows the chromatogram of a Grob mixture containing seven analytes (methanol, $n$-decane, $n$-undecane, $n$-nonaldehyde, 2,6-dimethylaniline, 2,6-dimethylphenol, and methyl dodecanoate). 2,6-Dimethylphenol presents stronger retention than 2,6-dimethylaniline, indicating the alkaline property of the silver column. Chromatographic peaks of $n$-nonaldehyde, 2,6-dimethylphenol, and 2,6-dimethylaniline are tailing due to the very polar property of the silver column. $n$-Decane, $n$-undecane, and methyl dodecanoate show symmetrical peaks with the best column efficiency of 72,673 plates $\mathrm{m}^{-1}$.

\subsubsection{Separation of Different Types of Compounds}

A mixture of different types of compounds ( $n$-alkanes, bromoalkanes, benzenes, ketones, and aldehydes) was applied to investigate the comprehensive chromatographic performance of the silver 
column. A sample composed of $n$-hexane, $n$-heptane, 1-bromobutane, $n$-octane, $p$-xylene, $o$-xylene, cyclohexanone, benzaldehyde, 1-bromooctane, n-dodecane, benzyl alcohol, and 1-bromododecane was successfully separated within $2.5 \mathrm{~min}$ in Figure 4c. The chemical structure, column efficiency and resolution of these compounds are shown in Table 1 . This indicates that the silver column possesses a high separation ability for different types of compounds through mixed retention mechanisms such as hydrophobic, dipole-dipole, and dipole-induced dipole interactions.

Table 1. Twelve compounds separated by the silver column in Figure 4c.

\begin{tabular}{|c|c|c|c|c|}
\hline Compounds & $\begin{array}{l}\text { Boiling } \\
\text { Point }\end{array}$ & Chemical Structure & $\begin{array}{l}\text { Column Efficiency } \\
\quad\left(\text { Plates } \mathrm{m}^{-1}\right)\end{array}$ & Resolution \\
\hline$n$-Hexane & 68.74 & & 12013 & 一 \\
\hline$n$-Heptane & 98.5 & & 5657 & 1.26 \\
\hline n-Butyl bromide & 101.6 & & 8864 & 1.09 \\
\hline$n$-Octane & 125.8 & & 14847 & 3.31 \\
\hline p-Xylene & 138.5 & & 2847 & 2.58 \\
\hline$o$-Xylene & 144.4 & & 11131 & 0.43 \\
\hline Cyclohexanone & 155.6 & & 1103 & 2.80 \\
\hline Benzaldehyde & 179 & & 6493 & 0.77 \\
\hline 1-Bromooctane & 201 & & 17142 & 1.34 \\
\hline$n$-Dodecane & 213 & & 74679 & 2.63 \\
\hline Benzyl alcohol & 205.4 & & 9754 & 3.30 \\
\hline 1-Bromododecane & 276 & & 110382 & 6.57 \\
\hline
\end{tabular}

\subsubsection{Repeatability of Chromatographic Separation}

Separation repeatability of the GC column is very important for its application. The column was tested by a repeated injection of the $n$-alkanes mixture (ten times). The chromatograms are shown in Figure S3. The relative standard deviations of retention times for ten $n$-alkanes are in the range of $0.073 \%-0.591 \%$. According to the results, the silver column exhibits a satisfactory chromatographic repeatability.

\section{Materials and Methods}

\subsection{Materials and Reagents}

3-Mercaptopropyltrimethoxysilane (98\%) was obtained from Qufu Chenguang Fine Chemical Co. (Qufu, China) and was purified by vacuum distillation before use. Toluene was dried by refluxing with sodium for $24 \mathrm{~h}$ and was distilled before use. $\mathrm{AgNO}_{3}$ and glucose were of analytical-grade quality and were obtained from Sinopharm Chemical Reagent Co. (Shanghai, China). All the other chemicals were of analytical-grade quality. The silica capillary $(0.20 \mathrm{~mm}$, i.d.) was purchased from Yongnian Ruifeng Chromatographic Apparatus Co., Ltd. (Handan, Hebei, China). 


\subsection{Apparatus}

An Agilent 7890A GC system (Agilent Technologies, Palo Alto, California, USA) equipped with a flame ionization detector (FID) and a split/splitless inlet was used. All chromatographic separations were performed under the following conditions: ultrapure nitrogen $(>99.999 \%)$ as a carrier gas and make-up gas, injection port at $200{ }^{\circ} \mathrm{C}$, split injection mode at a ratio of $100: 1$, and FID detector at $300{ }^{\circ} \mathrm{C}$. A field-emission scanning electron microscope (SEM, SUPRATM55, Carl Zeiss, AG, Heidenheim, Germany) and an energy-dispersive X-ray spectrometer (EDS, Oxford INCA X-Act, High Wycombe, England) were used for the characterization.

\subsection{Preparation of the Silver Column}

A silica capillary $(15 \mathrm{~m} \times 0.20 \mathrm{~mm}$ i.d. $)$ was filled with $0.1 \mathrm{~mol} \mathrm{~L}^{-1} \mathrm{NaOH}$ solution under $65^{\circ} \mathrm{C}$ for $1 \mathrm{~h}$ to expose the silanol groups on inner surface. Then, the capillary was successively rinsed with $0.1 \mathrm{~mol} \mathrm{~L}^{-1} \mathrm{HCl}$ and water for $60 \mathrm{~min}$ and $30 \mathrm{~min}$, respectively. Afterwards, the pretreated capillary was rinsed with methanol for $5 \mathrm{~min}$ and dried by nitrogen flow for the following process.

In order to strengthen the binding between the silver coating and the inner surface of the silica capillary, the capillary was modified by the mercapto groups before the functionalization with silver coating. Firstly, $0.5 \mathrm{~mL}$ of 3-mercaptopropyltrimethoxysilane was dissolved in $2.0 \mathrm{~mL}$ of toluene. Next, the above solution was injected into the pretreated silica capillary and stayed at $110{ }^{\circ} \mathrm{C}$ for $24 \mathrm{~h}$, and then the capillary was successively rinsed with toluene, ethanol, water, and methanol.

The functionalization of the capillary was performed by a modified method in our previous report [25]. The capillary modified with mercapto groups was filled by a reaction solution containing $0.4 \mathrm{~mol} \mathrm{~L}^{-1}$ of $\left[\mathrm{Ag}\left(\mathrm{NH}_{3}\right)_{2}\right]^{+}$and $0.4 \mathrm{~mol} \mathrm{~L}^{-1}$ of glucose at room temperature for $3 \mathrm{~h}$. After the modification, the capillary column presented a silvery color (Figure 1a). Then, the column with the silver coating was rinsed with water and methanol in turn. After being dried, the silver column was conditioned with $0.5 \mathrm{~mL} \mathrm{~min}-1 \mathrm{~N}_{2}$ from $50{ }^{\circ} \mathrm{C}$ to $150{ }^{\circ} \mathrm{C}$ at a rate of $5{ }^{\circ} \mathrm{C} \mathrm{min}-1$ and held at the final temperature for $3 \mathrm{~h}$.

\section{Conclusions}

In this work, a GC capillary column with a nanostructured silver coating was developed by a silver mirror reaction. The silver coating, about $80-120 \mathrm{~nm}$ in thickness, worked as the stationary phase, which could interact with various organic compounds, including $n$-alkanes, $n$-alcohols, 1 -bromoalkanes, and benzenes. The good chromatographic separation of these types of compounds could be obtained on the silver column, respectively. Furthermore, the silver column could separate twelve different types of compounds within $2.5 \mathrm{~min}$, based on a multiple retention mechanism, such as hydrophobic, dipole-dipole, and dipole-induced dipole interactions. This demonstrates that the silver column is promising for gas chromatographic separation. Future work will focus on the modification of the silver column by functionalizing the silver coating for further chromatographic separation.

Supplementary Materials: The supplementary materials are available online http://www.mdpi.com/1420-3049/ 24/24/4491/s1.

Author Contributions: Q.J. and M.S. designed the research. Q.J. and P.X. performed the experiments. Q.J. and J.F. analyzed the data. Q.J., P.X., J.F. and M.S. wrote and revised the manuscript. J.F. and M.S. were responsible for supervision and funding acquisition. All authors have read and approved the final version.

Funding: This research work was financially supported by the National Natural Science Foundation of China (NSFC, No. 21777054), the Shandong Provincial Natural Science Foundation of China (No. ZR2017MB043) and the fund of Gansu Agricultural University (Nos. 2017RCZX-10 and GAU-XKJS-2018-158).

Conflicts of Interest: The authors declare no conflict of interest. 


\section{References}

1. Hou, X.; Lu, X.; Tang, S.; Wang, L.; Guo, Y. Graphene oxide for solid-phase extraction of bioactive phenolic acids. Anal. Bioanal. Chem. 2017, 409, 3541-3549. [CrossRef] [PubMed]

2. Li, N.; Jiang, H.-L.; Wang, X.; Wang, X.; Xu, G.; Zhang, B.; Wang, L.; Zhao, R.-S.; Lin, J.-M. Recent advances in graphene-based magnetic composites for magnetic solid-phase extraction. TrAC-Trends Anal. Chem. 2018, 102, 60-74. [CrossRef]

3. Zhao, X.-E.; He, Y.; Zhu, S.; Xu, Y.; You, J.; Bai, Y.; Liu, H. Stable isotope labeling derivatization and magnetic dispersive solid phase extraction coupled with UHPLC-MS/MS for the measurement of brain neurotransmitters in post-stroke depression rats administrated with gastrodin. Anal. Chim. Acta 2019, 1051, 73-81. [CrossRef] [PubMed]

4. Wen, C.; Li, M.; Li, W.; Li, Z.; Duan, W.; Li, Y.; Zhou, J.; Li, X.; Zeng, J. Graphene deposited onto aligned zinc oxide nanorods as an efficient coating for headspace solid-phase microextraction of gasoline fractions from oil samples. J. Chromatogr. A 2017, 1530, 45-50. [CrossRef] [PubMed]

5. Yang, Y.; Qin, P.; Zhang, J.; Li, W.; Zhu, J.; Lu, M.; Cai, Z. Fabrication of nanoscale graphitic carbon nitride/copper oxide hybrid composites coated solid-phase microextraction fibers coupled with gas chromatography for determination of polycyclic aromatic hydrocarbons. J. Chromatogr. A 2018, 1570, 47-55. [CrossRef] [PubMed]

6. Han, S.; Feng, J.; Ji, X.; Li, C.; Wang, X.; Tian, Y.; Sun, M. Nano- $\mathrm{MoO}_{3}$ for highly selective enrichment of polycyclic aromatic hydrocarbons in in-tube solid-phase microextraction. J. Sep. Sci. 2019, 42, 3363-3371. [CrossRef] [PubMed]

7. Wang, X.; Sun, J.; Zhao, X.-E.; Xu, Y.; Sun, L.; Zhu, S.; You, J.; Wang, X. Stable isotope labeling derivatization coupled with magnetic dispersive solid phase extraction for the determination of hydroxyl-containing cholesterol and metabolites by in vivo microdialysis and ultra-high performance liquid chromatography tandem mass spectrometry. J. Chromatogr. A 2019, 1594, 23-33.

8. Wang, S.; Li, X.; Liu, Y.; Zhang, C.; Tan, X.; Zeng, G.; Song, B.; Jiang, L. Nitrogen-containing amino compounds functionalized graphene oxide: Synthesis, characterization and application for the removal of pollutants from wastewater: A review. J. Hazard. Mater. 2018, 342, 177-191. [CrossRef]

9. Qin, P.; Yang, Y.; Zhang, X.; Niu, J.; Yang, H.; Tian, S.; Zhu, J.; Lu, M. Highly efficient, rapid and simultaneously remove cationic dyes from aqueous solution with monodispersed mesoporous silica nanoparticles as the adsorbents. Nanomaterials 2018, 8, 1-14.

10. Zhang, H.; Qiao, X.; Cai, T.; Chen, J.; Li, Z.; Qiu, H. Preparation and characterization of carbon dot-decorated silica stationary phase in deep eutectic solvents for hydrophilic interaction chromatography. Anal. Bioanal. Chem. 2017, 409, 2401-2410. [CrossRef]

11. Cai, T.; Zhang, H.; Li, Z.; Mustafizur Rahmana, A.; Qiu, H. A new nano-on-micro stationary phase based on nanodiamond bonded on silica for hydrophilic interaction chromatography. RSC Adv. 2016, 6, 32757-32760. [CrossRef]

12. Herrera-Herrera, A.V.; González-Curbelo, M.Á.; Hernández-Borges, J.; Rodríguez-Delgado, M.Á. Carbon nanotubes applications in separation science: A review. Anal. Chim. Acta 2012, 734, 1-30. [CrossRef]

13. Karwa, M.; Mitra, S. Gas chromatography on self-assembled, single-walled carbon nanotubes. Anal. Chem. 2006, 78, 2064-2070. [CrossRef] [PubMed]

14. Yuan, L.-M.; Ren, C.-X.; Li, L.; Ai, P.; Yan, Z.-H.; Zi, M.; Li, Z.-Y. Single-walled carbon nanotubes used as stationary phase in GC. Anal. Chem. 2006, 78, 6384-6390. [CrossRef] [PubMed]

15. Stadermann, M.; McBrady, A.D.; Dick, B.; Reid, V.R.; Noy, A.; Synovec, R.E.; Bakajin, O. Ultrafast gas chromatography on single-wall carbon nanotube stationary phases in microfabricated channels. Anal. Chem. 2006, 78, 5639-5644. [CrossRef]

16. Hussain, C.M.; Saridara, C.; Mitra, S. Self-assembly of carbon nanotubes via ethanol chemical vapor deposition for the synthesis of gas chromatography columns. Anal. Chem. 2010, 82, 5184-5188. [CrossRef] [PubMed]

17. Qu, Q.; Shen, Y.; Gu, C.; Gu, Z.; Gu, Q.; Wang, C.; Hu, X. Capillary column coated with graphene oxide as stationary phase for gas chromatography. Anal. Chim. Acta 2012, 757, 83-87. [CrossRef] [PubMed]

18. Zheng, Y.; Qi, M.; Fu, R. Graphitic carbon nitride as high-resolution stationary phase for gas chromatographic separations. J. Chromatogr. A 2016, 1454, 107-113. [CrossRef] [PubMed] 
19. Gross, G.M.; Grate, J.W.; Synovec, R.E. Monolayer-protected gold nanoparticles as an efficient stationary phase for open tubular gas chromatography using a square capillary model for chip-based gas chromatography in square cornered microfabricated channels. J. Chromatogr. A 2004, 1029, 185-192. [CrossRef] [PubMed]

20. Gross, G.M.; Nelson, D.A.; Grate, J.W.; Synovec, R.E. Monolayer-protected gold nanoparticles as a stationary phase for open tubular gas chromatography. Anal. Chem. 2003, 75, 4558-4564. [CrossRef]

21. Gross, G.M.; Grate, J.W.; Synovec, R.E. Development and evaluation of gold-centered monolayer protected nanoparticle stationary phases for gas chromatography. J. Chromatogr. A 2004, 1060, 225-236. [CrossRef]

22. Qu, Q.-S.; Shen, F.; Shen, M.; Hu, X.-Y.; Yang, G.-J.; Wang, C.-Y.; Yan, C.; Zhang, Y.-K. Open-tubular gas chromatography using capillary coated with octadecylamine-capped gold nanoparticles. Anal. Chim. Acta 2008, 609, 76-81. [CrossRef] [PubMed]

23. Le Ouay, B.; Stellacci, F. Antibacterial activity of silver nanoparticles: A surface science insight. Nano Today 2015, 3, 339-354. [CrossRef]

24. Liu, Z.; Wang, L.; Bian, W.; Zhang, M.; Zhan, J. Porous silver coating fiber for rapidly screening organotin compounds by solid phase microextraction coupled with surface enhanced Raman spectroscopy. RSC Adv. 2017, 7, 3117-3124. [CrossRef]

25. Feng, J.; Sun, M.; Li, J.; Liu, X.; Jiang, S. A novel silver-coated solid-phase microextraction metal fiber based on electroless plating technique. Anal. Chim. Acta 2011, 701, 174-180. [CrossRef]

26. Tian, Y.; Zhou, J.; Feng, J.; Wang, X.; Luo, C.; Sun, M. A silver fiber prepared by a facile method for solid-phase microextraction of polycyclic aromatic hydrocarbons. Environ. Chem. 2018, 14, 451-457. [CrossRef]

27. Shen, L.; Ji, J.; Shen, J. Silver mirror reaction as an approach to construct superhydrophobic surfaces with high reflectivity. Langmuir 2008, 24, 9962-9965. [CrossRef]

28. Zuo, Y.; Tang, J.; Fan, C.; Tang, Y.; Xiong, J. An electroless plating film of palladium on 304 stainless steel and its excellent corrosion resistance. Thin Solid Films 2008, 516, 7565-7570. [CrossRef]

29. Gu, C.D.; Xu, X.J.; Tu, J.P. Fabrication and wettability of nanoporous silver film on copper from choline chloride-based deep eutectic solvents. J. Phys. Chem. C 2010, 114, 13614-13619. [CrossRef]

30. Zhang, P.; Qin, S.; Qi, M.; Fu, R. Cucurbit[n]urils as a new class of stationary phases for gas chromatographic separations. J. Chromatogr. A 2014, 1334, 139-148. [CrossRef]

Sample Availability: Not available.

(C) 2019 by the authors. Licensee MDPI, Basel, Switzerland. This article is an open access article distributed under the terms and conditions of the Creative Commons Attribution (CC BY) license (http://creativecommons.org/licenses/by/4.0/). 